\title{
Exercise-induced bronchospasm at low temperature in elite runners
}

\author{
Ilkka J Helenius, Heikki O Tikkanen, Tari Haahtela
}

\section{Department of \\ Allergic Diseases, \\ Helsinki University \\ Central Hospital, \\ SF-00250 Helsinki, \\ Finland \\ I J Helenius \\ T Haahtela}

Research Institute for Olympic Sports,

Jyväskylä, Finland

H O Tikkanen

Correspondence to:

I Helenius.

Received 7 September 1995

Returned to authors

4 December 1995

Revised version received

10 January 1996

10 January 1996

6 February 1996

\begin{abstract}
Background - Healthy elite runners often report bronchial symptoms when training in subzero temperatures. The occurrence and causes of exercise-induced bronchospasm after heavy exercise in cold air were investigated in elite runners.

Methods - Thirty two non-asthmatic runners, mostly from Finnish national teams, volunteered to take part in the study. They answered a questionnaire and were subjected at subzero temperature to a heavy exercise challenge test combined with lung function testing.
\end{abstract}

Results - Sixteen of the runners were atopic on skin prick tests. The mean (SD) maximal change in forced expiratory volume in one second $\left(F_{E V}\right)$ after the exercise challenge was $-4.8(7 \cdot 1) \%$ in the atopic runners, and $+2 \cdot 1(3 \cdot 4) \%$ in the non-atopic runners. When the mean maximal change in $\mathrm{FEV}_{1}$ minus $2 \mathrm{SD}(-4 \cdot 7 \%)$ of the exercise response of the non-atopic runners was taken as the lower limit of a "normal" result, eight of the atopic runners responded abnormally.

Conclusions - Heavy exercise at temperatures below zero causes bronchospasm in a high proportion of elite runners with atopy. Although the changes in lung function are mostly small, they may affect the maximal performance of atopic runners. Non-atopic runners are not affected. (Thorax 1996;51:628-629)

Keywords: exercise-induced bronchospasm, atopy, lung function.

Climatic conditions, pre-exercise forced expiratory volume in one second (FEV) and maximal post-exercise change in FEV $V_{1}$ in exercise challenge test

\begin{tabular}{|c|c|c|c|c|c|}
\hline & $\begin{array}{l}\text { Temperature } \\
\left({ }^{\circ} \mathrm{C}\right)\end{array}$ & $\begin{array}{l}\text { Water } \\
\text { content }\left(\mathrm{g} / \mathrm{m}^{3}\right)\end{array}$ & $\begin{array}{l}\text { Pre-exercise } \\
F E V_{l}(1) \\
\left(\% \text { predicted }{ }^{*}\right)\end{array}$ & $\begin{array}{l}\text { Maximal } \\
\text { change in } \\
F E V_{l}(\%)\end{array}$ & $\begin{array}{l}\text { Maximal } \\
\text { change in } \\
F E V_{t}(m l)\end{array}$ \\
\hline \multicolumn{6}{|c|}{ Non-atopic runners $(n=16)$} \\
\hline Mean & $-6 \cdot 6$ & $2 \cdot 8$ & $4 \cdot 7(106)$ & $+2 \cdot 1$ & +80 \\
\hline Range & -13 to -1 & $1 \cdot 4$ to 4.2 & & -2 to +10 & $\begin{array}{l}-120 \text { to } \\
+360\end{array}$ \\
\hline SD & $4 \cdot 9$ & $1 \cdot 2$ & $0 \cdot 8(10)$ & $3 \cdot 4$ & 150 \\
\hline \multicolumn{6}{|c|}{ Atopic runners $(n=16)$} \\
\hline Mean & $-6 \cdot 2$ & $2 \cdot 8$ & $5 \cdot 1(105)$ & $-4 \cdot 8$ & -250 \\
\hline Range & -13 to -1 & $1 \cdot 4$ to $4 \cdot 2$ & $\begin{array}{l}3 \cdot 7(88) \text { to } \\
6 \cdot 4(121)\end{array}$ & -25 to +5 & $\begin{array}{l}-1450 \text { to } \\
+250\end{array}$ \\
\hline SD & $4 \cdot 8$ & $1 \cdot 2$ & $0 \cdot 7(11)$ & $7 \cdot 1$ & 390 \\
\hline
\end{tabular}

* Reference values are those for adult Finns (Viljanen A, Scand f Clin Lab Invest 1982;42(Suppl 159):1-50.

Healthy elite runners often report bronchial symptoms such as cough, mucus production, and even wheezing when training in subzero temperatures. ${ }^{1}$ However, exercise-induced bronchospasm has been sparsely studied in elite athletes. Running is the most effective way to provoke exercise-induced bronchospasm and it is exacerbated by inhaling cold dry air. ${ }^{2}$ Thus, we investigated the occurrence and causes of exercise-induced bronchospasm after heavy exercise in cold air in runners competing at international level.

\section{Methods}

Thirty two runners (26 from Finnish national teams) volunteered to participate in the study. None had a history of asthma diagnosis or use of asthma medication. The runners (who specialised in distances from 400 metres to the marathon) had competed for a mean of 9.4 (range 2-20) years and had run a mean distance in training of 3670 (range 2000-7100) kilometres in the previous year. The runners were divided into atopic and non-atopic groups based on skin prick test results. All subjects gave their informed written consent and the protocol was approved by the local ethics committee.

\section{STUDY DESIGN}

The study was carried out in February and March 1994. Exercise challenge tests were performed at the Finnish Sport Institute (Vierumäki, Finland). On a later day the runners completed a questionnaire and were subjected to a resting spirometric examination and skin prick tests at the Helsinki University Central Hospital.

The questionnaire enquired about the occurrence of asthma, medication, and exerciseinduced symptoms. The latter were considered to occur if symptoms of breathlessness, wheeze, or cough had been observed repeatedly during the previous year. The answers were controlled in personal interviews.

Spirometric tests at rest were carried out according to the recommendations of the American Thoracic Society. ${ }^{3}$

Skin prick tests were made with 10 airborne allergen extracts (Soluprick SQ, ALK, Denmark): birch, timothy, meadow fescue and 
mugwort pollen, horse, cat, dog, and cow dander, Dermatophagoides pteronyssinus, and Cladosporium herbarum. A subject was classified as atopic if any allergen caused a weal of $3 \mathrm{~mm}$ or more in diameter.

Exercise challenge tests were carried out at low temperature (table). The tests consisted of running 2000 metres at $85 \%$ of their personal maximum heart rate, calculated from 205 beats/min minus half their age, without warm up. Forced expiratory volume in one second $\left(\mathrm{FEV}_{1}\right)$ was measured immediately before and at 4,10 , and 20 minutes after the exercise challenge using a pocket sized spirometer (Escort, Vitalograph, UK).

\section{STATISTICAL ANALYSIS}

Results are expressed as means (SD). Statistical comparisons were calculated with the Student's unpaired $t$ test. Two tailed p values below 0.05 were considered significant.

\section{Results}

Sixteen of the 32 runners were atopic on skin prick tests. Five of the atopic runners but none of the non-atopic subjects reported having exercise-induced bronchial symptoms. Both the atopic and non-atopic runners had mean resting spirometric parameter values close to or higher than predicted. There were no significant differences between the two groups.

The atopic and non-atopic runners ran the exercise challenge test in similar climatic conditions and both groups had similar FEV values before the run (table). The mean (SD) running times of $7 \mathrm{~min} 12 \mathrm{~s}(56 \mathrm{~s})$ and $7 \mathrm{~min}$ $25 \mathrm{~s}(44 \mathrm{~s})$, respectively, as well as the maximal heart rate of $173(8) / \mathrm{min}$ and $178(11) / \mathrm{min}$, respectively, during the run were also similar.

When $F E V_{1}$ values were measured after the exercise challenge the values had decreased from pre-exercise values in most atopic runners and increased in most non-atopic runners. The mean (SD) maximum change in $\mathrm{FEV}_{\mathfrak{i}}$ was $-4 \cdot 8(7 \cdot 1) \%$ for atopic runners and $+2 \cdot 1$ $(3.4) \%$ for non-atopic runners $(p<0.002)$ (table). As a subgroup, the 11 atopic but symptom-free runners also hađ a significantly larger change in $\mathrm{FEV}_{1}$ on exercise challenge than the non-atopic runners with a mean (SD) maximal value of $-5.1(7.7) \%(\mathrm{p}<0.003)$.

We decided to use the mean maximum change in $F E V_{1}$ minus $2 S D(-4-7 \%)$ of the non-atopic runners as a lower limit of a normal exercise test result. Eight $(50 \%)$ of the atopic runners had a maximal post-exercise change in $\mathrm{FEV}_{1}$ below this limit (table). In absolute terms the decreases in $\mathrm{FEV}_{1}$ ranged from $170 \mathrm{ml}$ to $1450 \mathrm{ml}$ in these eight runners. None of the non-atopic runners responded abnormally to exercise.

\section{Discussion}

Heavy exercise under outdoor subzero winter conditions caused an abnormal bronchospasm in a high proportion of those elite runners who were atopic as judged by skin tests. Exerciseinduced bronchospasm may influence athletic performance by increasing ventilatory cost and decreasing maximal ventilation. ${ }^{4}$ Studies in this field are few, and this is probably the first investigation in which the effect of a challenge test resembling normal outdoor winter training has been examined.

Deal et $a l^{5}$ performed exercise testing with inhalation of subfreezing air in patients with hay fever and found significant reductions in FEV 1 only in those patients who had a history of past wheezing. We also found that atopic symptom-free runners had significantly larger reductions in $\mathrm{FEV}_{\mathrm{I}}$ after exercise challenge than non-atopic runners.

In elite athletes a "normal range" of lung function change after exercise has not been established. In this study the definition of a normal response was based on the results of non-atopic runners. This approach has separated the exercise response of asthmatic children from that of controls and children with other chronic lung diseases. ${ }^{6}$

Although the elite runners studied were a small selected group subjected to extreme conditions, the findings indicate that atopic athletes are at risk of suffering slight bronchospasm when training or competing in winter, even if they have no other indications of asthma.

We thank Dr Fred Biörksten, Mrs Leena Petman, Mrs Alli Tallqvist, Mrs Anne Bruce, and Mr Timo Vuorimaa for technical help. This study was supported by grants from the Finnish Allergy and Asthma Federation, Finnish Olympic Committee, and Vàinơ and Laina Kivi Foundation.

1. Tikkanen HO, Helenius $\mathrm{fJ}$. Asthma in runners. BMF 1994; 309: 1087 .

2 Godfrey S. Exercise- and hyperventilation-induced asthma. In: Clark TIH, Godrey S, Lee TH, eds. Asthma. 3rd ed. Londin: Chapman and Hall, 1992:73-102.

3 American Thoracic Society. Standardization of spirometry 1987 update. Am Rev Respir Dis 1987;136:1285-98.

McFaddien ER. Exercise performance in the asthmatic. Am Rev Respir Dis 1984;129 (Suppl):S84-7.

5 Deal EC, McFadden ER, Ingram RH, Breslin. FJ, Jaeger Jf. Airway responsiveness to cold air and hyperpmea in mormal subjects and in those with hay fever and asthma. Am Rev Respir Dis 1980;121:621-8.

6 Avital A, Springer C, Bar-Yishay Ey Godfrey S. Adenosine, methachotine, and exercise challenges in children with asthma or paediatric chronic obstructive pulmonary disease. Thorax 1995;50:511-6. 